\title{
Laryngopharyngeal Spray, Solution Dosage Form
}

National Cancer Institute

\section{Source}

National Cancer Institute. Laryngopharyngeal Spray, Solution Dosage Form. NCI

Thesaurus. Code C149628.

Liquid preparation consisting of a solution intended for spraying onto the laryngopharynx for a local effect. 